\title{
Benevolent Capitalism: Entrepreneurship in Action, Community Reinvestment and National Development
}

\author{
Suleiman M. Barnabas \\ Department of Sociology College of Development Studies Covenant University
}

\begin{abstract}
Capitalism has been the most criticized form of economic system because it is generally believed by critics that the system is inherently exploitative, demeaning and suppressive. In the very face of the avalanche of criticisms, capitalist system continues to successfully transverse the whole globe as the most promising economic system in achieving individual progress and national development. Thus, we must be honest to ourselves that the forces behind capitalism are more than ever fortified to see that no opposing forces fruitfully challenge or destroys the system, so that we must necessarily move from challenging the system as a whole, but rather the identifiable ills of the system, with a view to strongly appealing to the benefactors of the capitalist system, both as individuals and nations, to use the proceeds of capitalism to positively impact the lives of the poor people and nations of the world. In this paper, it is argued that benevolent capitalism, if consciously pursued by business stakeholders, will result in community reinvestment and national development.
\end{abstract}

Keywords: Benevolent entrepreneurship, Capitalism, Entrepreneurship in action, Community reinvestment, National development

\section{Introduction}

Capitalism represents a social system that that operates on the principle of individual rights, and it includes a combination of political, legal and economic ideals. Politically, it claims to champion freedom (laissez-faire); legally it claims rule of law; and economically it represents and champions free-market. The concept of capitalism in this paper is in the economic sense of the term.

Benevolent capitalism refers to that form of capitalism that is channeled to the betterment of the greater number of people in terms of provision of goods and services at the most affordable prices as well as the most generous remuneration package for workers.

But as businesses continue to direct their resources for the good of people and planet, their efforts to use capitalism for the greater good can be met with success.

Benevolent capitalism means responsible socialism. It is that form of capitalism that will harness market forces to meet the needs of the less privileged in our society as well as the needs of poor nations, at the global level.

Bill Gates advocated for benevolent capitalism when he beckoned on the benefactors of capitalism "to find a way to make the aspects of capitalism that serve wealthier people serve poorer people as well."

The surest way to address the shortcomings of capitalism is for the capitalists to use their fortunes to address the needs of the larger society. They have to harness their resources to fight the ills of society, namely poverty and diseases among others. This is the surest means of ensuring that advances in science, technology, medicine, etc., etc. does not serve only the interest of the rich, but also the poor peoples of the world, rural and urban altogether.

The advantage of benevolent capitalism is that it guarantees not just personal safety and economic freedom but collective safety and economic freedom. Reisman (2002) summarizes this point when he argued that:

"Freedom means the absence of the initiation of physical force. When one is free, one is safesecure - from common crime, because what one is free of or free from is precisely acts such as assault and battery, robbery, rape, and murder, all of which represent the initiation of physical force."

The crude exploitation that characterizes typical capitalism is determinedly negated in implementing benevolent capitalism. In such a capitalist system, it is not just about the division of labour, but also the division of the rate of return for society members which could take the form of corporate social responsibility.

\section{Entrepreneurship In Acton}

Entrepreneurship is the quality and skill required to become an entrepreneur. It refers to the capacity required for identifying and generating innovative business ideas, mobilizing resources, organizing production, marketing the products, managing the risks and constantly working for growth and success of the business. Entrepreneurship opportunity may entail: 
1) Pioneering a truly innovative product

2) Devising a new business model

3) Creating a better or cheaper version of an existing product

4) Targeting an existing product to new sets of customers.

These opportunity types are not mutually exclusive. Since they are pursuing a novel opportunity, even though lacking access to required resources, entrepreneurs face considerable risk, which comes in four main types that includes demand risk, technology risk, execution risk and financing risk. Demand risk relates to prospective customers' willingness to adopt the solution envisioned by the entrepreneur. Technology risk is high when engineering or scientific breakthroughs are required to bring a solution to fruition. Execution risk relates to the entrepreneur's ability to attract employees and partners who can implement the venture's plans. Financing risk relates to whether external capital will be available on reasonable terms. The entrepreneur's task is to manage this uncertainty, while recognizing that certain risks cannot be influenced by their actions. Thus, the following attributes are very crucial to entrepreneurship: self-direction, self-nurturing, tolerance for uncertainty and action-oriented, among others.

Entrepreneurship in Action entails the unique opportunity of conceiving, launching, and operating a real business, including strategy, sales and marketing, finance and accounting, operations, human resources, and information technology. It means that the entrepreneur seeks through potential business opportunities, develop the concepts, determine the resources required, and acquire the resources to launch the business in ways that delivers profitability while simultaneously advancing economic and social conditions in the communities where companies operate. The benevolent nature of this type of entrepreneurship makes the entrepreneur to prioritize the economic and social needs of the people above the traditional motive of entrepreneurship which is profit maximization.

The entrepreneur in action takes advantage of the crisscrossing needs of business and the community while minimizing the differences. Opportunities to create shared value must be tied closely to a company's core business operations, which can bring skills, resources, and new operating practices to improve productivity while simultaneously benefiting the community. Entrepreneurship in action enables residents of disadvantaged communities to prosper in the market system through the efforts of business.

It also encompasses the implementation of the business plan, management of the business, and the ability to determine the exit strategy for the business (when it becomes inevitable).

The main benefit of entrepreneurship in action is that it fills the gap left by governments which, for a variety of reasons, are unable to generate and implement solutions that would improve the wellbeing of the citizens in spheres such as health, education, housing and the environment. Also, entrepreneurship in action produces win-win situations that combine the delivery of social value with profitmaking. Finally, such efforts will also give purpose to capitalism and represent organization's best chance to legitimize business again, at least in the hearts of the 'victims' and opponents of capitalism.

\section{How Can Entreprenurship Save The Nigerian Communities?}

Every day, we are faced with the realities of poverty, unemployment, inadequate services and criminality in the Nigerian communities. The solution to getting rid of these menaces must not be left to the effort of preachers and government alone. In fact, they have not succeeded at doing so in any society in history! Those societies that have successfully curbed social menace and reasonably tackled poverty were the societies that have used entrepreneurship as a tool to meeting the needs of their citizenry. Following Porter's model, big organizations can use business strategy to drive community revitalization as a tool to enhance their competitiveness by growing and mentoring local entrepreneurs leading to local benefits in terms of employment, career ladders, and community revitalization. Efforts like these will spawn local businesses and cause ripple effects to transform inner city economies.

Thus, entrepreneurship can save or protect the Nigerian communities from the perils of lack of access to the good things of life by offering the following.

i. Employment: with the government openly admitting that it has failed to create the needed employment opportunities for Nigerians, especially young graduates from tertiary institutions, there is no doubting the fact that the baton has been passed on to entrepreneurs to create employ the ever increasing number of jobless Nigerians.

ii. Poverty reduction: entrepreneurship can help reduce the current trend of poverty in Nigeria. If you visited highly distressed cities in Nigeria, such as Ajegunle, Maraba, or Lugbe in Abuja, one will be amazed to witness the level of poverty and social inequality in our country. This Population of migrants from diverse villages in Nigeria settles in these areas characterized by poor quality housing, far lower than average educational standards in poorly staffed schools that have in turn led to many unskilled jobs creating a general lower than average income as well as a high dependency on menial jobs. 
iii. Crime reduction: due to joblessness and poverty, Nigerians who would have led a decent and responsible lives have taken to criminal activities to enable then cope. So, we witness high rates of crime such as theft, assaults, pause-snatching, drug-related incidents and robberies. However, with the tool of entrepreneurship, Nigerian communities can be spared of these upheavals. This can be achieved by engaging the people in entrepreneurship activities, trainings and skills acquisition programmes, etc., etc.

iv. Provision of services through corporate social responsibility: entrepreneurship can address the problem of inadequate services in Nigerian communities. The problems of visual pollution and inadequate collection services that has created a situation where streets are littered with rubbish and wastelands being used as dumping grounds can be adequately and profitably addressed through entrepreneurship. This is particularly in the case of entrepreneurial skill and ability to turn wastes into wealth.

\section{Needs And Values In Identified Communities Such As Ajegunle In Lagos, And Maraba And Lugbe In Abuja}

The needs and values in the three communities or suburban areas of Ajegunle, Maraba and Lugbe are quite similar. There is the concentration of economic distress in these areas measured by poverty rates, income levels, and unemployment and the attendant problem of criminal activities. Thus, establishing industries or locating businesses, even if they are small firms can have a tremendous impact on these inner cities in terms of job creation and overall economic revitalization. This is crucial because "Jobs anywhere" or jobs in the mainstream cities of Abuja, Lagos, Kano, Port Harcourt, etc. are not enough, so that inner city residents can hardly access jobs in the rest of the developed cities of the country.

Also, people in these distressed areas of the cities can be trained and empowered with credit facilities to startup their own small businesses. Those who require certain skills to be able to work in firms can also be trained and equipped with the necessary skills to enable them gain employment in the available or emerging work opportunities. As a competitive advantage strategy, inner city firms must leverage on the advantages of the local workforce by hiring a higher percentage of inner city workers. More than jobs, however, inner city communities need small businesses. . Not only do small businesses create wealth for employees and owners, but those located in disadvantaged areas hire disproportionately from the local community.

What is the key to growth in both rural and distressed urban areas? Entrepreneurship, nay, benevolent entrepreneurship is the answer. There is no doubt entrepreneurship require resource location and mobilization for development purpose in rural and urban centres. Thus, location matters but does not determine success as growing inner city companies succeed in both advantageous and disadvantageous environments (Porter, 1995).

\section{Michael Porter On "Inner City Economics"}

Porter's article on the "Inner City Economics" was a clarion call to address the economic distress of inner cities. $\mathrm{He}$ warned that the lack of businesses and jobs in disadvantaged urban areas fuels not only a crushing cycle of poverty but also crippling social problems such as drug abuse and crime. The article shows that not only can companies thrive in the inner city, but there are also competitive advantages to locating businesses in the inner city. Thus, Michael E. Porter urges large organizations to invest in small businesses in inner cities.

He strongly harangued that the efforts of the past several decades to revitalize inner cities have failed despite the investment of substantial resources because the social programmes that were put in place was not matched with a coherent economic strategy. Thus, he argued that the best way to salvage inner city economy is by proliferating and growing inner city businesses through private, for-profit initiatives and investment based on economic self-interest and genuine competitive advantage. Furthermore he reasoned that such economic model must begin with the premise that inner city businesses must be profitable and positioned to compete on a regional, national, and even international scale. He asserted that governments and stakeholders should move from spasmodic or irregular approaches to addressing inner city predicament that have usually taken the form of subsidies, preference programs, or expensive efforts to stimulate economic activity in tangential or vague fields such as housing, real estate, and neighborhood development, to an economic strategy that is anchored on private, for-profit initiatives and investment based on economic self-interest and genuine competitive advantage -- not through artificial inducements, charity, or government mandates.

Thus, in essence, Porter's view is that social programmes which are meant to redistribute wealth are not sufficient and as such cannot solve the problems of poverty and crime in inner city, but that they can only be good enough when they complement sound economic strategies of wealth creation which he considers as the real need and real opportunities for the establishment of a sustainable economic base of the inner city. 


\section{Lessons Nigerian Communities Must Learn From Porter's Analysis}

The following lessons are important for Nigerian communities:

i. Poverty reduction, nay, development cannot be achieved by soliciting for charity donations from individuals or organizations

ii. Communities must tap into identified opportunities for entrepreneurial activities from which they can create wealth for self-sustenance

iii. Partner with the private sector for redevelopment of distressed areas (suburbs)

iv. Use statute-based apparatus to contribute to public investment related to renovation of deteriorating properties

v. Focus on the needs, issues and concerns of the community in redevelopment by making valuable and creative contributions to distressed communities needing renewal and reinvestment

vi. Provide leadership on redevelopment issues: this can be achieved by diffusion of migrant values via a sense of solidarity with members of concerned communities

vii. Educate and dialogue with the community about urban renewal programmes

\section{Addressing Push And Pull Factors In Community Revitalization}

Push factors are the dynamics within a country of origin which 'forces' people to emigrate or relocate either from source country to destination country or from rural to urban areas. These factors include unemployment, famine, war, political instability, etc., etc. Pull factors, on the other hand, are those features of destination countries (or urban cities) which attracts immigrants. These pull factors include: prosperous labour markets, better overall living conditions (the 'good life'), etc., etc.

From the foregoing, it becomes clear that government must endeavor to create favourable environments and conditions that will make rural dwellers to be useful to their communities without 'running' from their communities in search of green pastures, that they may not even be able to get in the urban areas. These will include building good schools and hospitals, constructing good roads, building recreation sites, and building industries in rural areas that can employ the youth population. Also, people can be trained and equipped with skills through skills acquisition programmes that will make them entrepreneurially valuable to rural and deteriorating, stagnated and distressed communities.

Recreation-oriented industries offer a logical fit -particularly sports and sports / leisure-related management. Recommend promoting environment for businesses needing access to nature and recreation, particularly professionals with the luxury of "operating from anywhere", especially those who are interested in smaller-town environments with access to culture and natural recreation.

For example, Covenant University has attracted eminent professors and people with urban values to Ota because the environment is considered safe and serene which is similar to those of Ikoyi, Lekki, Victoria Island, Port-Harcourt and Abuja cities. In the same way, entrepreneurs and governments can create the enabling environment that will address migration and immigration values that normally explain the unwillingness of people to live, work and contribute to rural areas and inner cities.

\section{Roles Of Stakeholders In Community Reinvestment (Renewal) And Community Deveopment}

There must be some form of practical guidance for engaging partners in projects that may affect them. Stakeholders' engagement involves the process of working collaboratively with and through groups of people affiliated by geographic proximity, special interest, or similar situations to address issues affecting the wellbeing of poverty-inflicted communities. As earlier stated, entrepreneurship in action requires an all-inclusive approach or methodology to tackling the social and economic deprivations of distressed communities (Cohen and Zysman, 1987). Thus, there are important and helpful roles expected of key stakeholders such as the government, community leaders, traditional rulers, elites, youth and women in making sure the objective of community reinvestment (renewal) and community development becomes successful. These expected roles by the various stakeholders are discussed below.

\section{Government}

In a perfect world, it would be better to do without government intervention. But we don't live in a perfect world, and so the government's role, especially in a developing economy like ours cannot be over emphasized. Governments should design programs that minimize bureaucracy and political interference, leaving the market as free as possible--not so much for ideological reasons but because in the long run, only genuinely market- based investment will take root and connect inner cities to the mainstream economy. The government having realized that public-private solutions are needed to grease the way for community reinvestment or renewal and community development through entrepreneurship, must take decisions aim at attracting developers with tax credits and low-interest loans even as they prepare a commercial infrastructure and incubate a local business culture. This is most required as the economy of the local community is not strong enough or attractive 
enough so far to support market-rate investment without some incentives. The government can also be a major source of revenue for fast growing inner city businesses. This has been the situation in the United States of America, and the practice can be replicated here in Nigeria by Federal, State and Local governments.

\section{Community Leaders}

They can play the role of Educating and dialoguing with the community about urban renewal. This was what the Fashola administration in Lagos State did through Ajegunle community leaders when it planned, unsuccessful though, to relocate the people so as to revitalize Ajegunle. Community leaders can also acquire blighted, deteriorated real property for preservation or restoration of historic sites. They also can partner with the private sector for redevelopment of distressed areas by focusing on the needs, issues and concerns of the community in redevelopment

\section{Elites}

Help in identifying and attracting strategic alliances and integrate with unique urban / natural connections (Eisinger, 1988). They can also help in defining role of urban renewal in community development and establishing benchmarks for projects, prioritize activities and promote flagship location capable of attracting visitors.

\section{Traditinal Rulers}

Can help entrepreneurs and organizations gain enhanced knowledge, more linkages with other community members and entities, and create goodwill and help lay the groundwork for subsequent collaborations with other 'partners in progress'. They can also caution and call their youths to order whenever crises between firms and unnecessary demands from youth arise.

\section{Youth}

The knowledge and skills of the public involved in the project can be enhanced, and their contributions can be recognized (possibly through financial rewards). These efforts foster goodwill and help lay the groundwork for subsequent collaborations also. Similarly, participating in the community renewal process becomes easier in them and brings benefits to participating youth. Apart from employing educated and skilled youths in the locality, unskilled youths could be employed as vigilante officers to provide security to lives and properties in the communities.

\section{Women}

Women are likely to be more receptive to the renewal and development effort as well as reap greater benefits from it. Educating and empowering women in the process is sure to result in reducing poverty resulting from traditional inequality and gender discrimination that is prevalent in rural and inner cities which thrives on the survival of the fittest.

The potential benefits of participation for community members, elites, and professionals include opportunities for networking, access to information and resources, personal recognition, learning, a sense of helping to solve community problems, improved relationships among stakeholders, increased capacity for problem solving, and contact with hard-to-reach populations (Butterfoss and Kegler, 2002).

Finally, when all these stakeholders are properly utilized, then the process can truly ensure empowerment, participation and self-determination. Community members and organizations will participate if they perceive that the benefits of participation outweigh the effort required

\section{Addressing the Challenges Posed By Poverty In The Inner Cities Of Nigerian Communities Development of an inclusive vision of high growth entrepreneurship}

We must engage in tirelessly communicating a coherent message to all of the stakeholders and residents in the community, emphasizing the entrepreneurial benefits of dignified job creation, quality of the environment, and innovative capacity. This implies engaging diverse stakeholders to define for themselves the role they would play in bringing about entrepreneurial-based solution to poverty.

We must engage our mind with innovative ideas to identify opportunities in the community, usually where most people think it doesn't exist, and mobilize resources to achieve the entrepreneurial objective. Also by soliciting for and mobilizing resources for urban renewal plan that promotes redevelopment of devastated area through public- private partnerships

Invest time: we will need to invest substantial time developing proposals and persuading the stakeholders that it is worth their while to make those investments that we would have identified. Through partnerships and collaboration, we should advance sound urban planning and design, facilitate development and redevelopment 
within all urban renewal areas that balanced, sustainable environments where people, live, work and come together as community.

\section{Conclusion}

What this paper has attempted to emphasize is the fact that capitalism can become a tool for community revitalization and national development through the concept of benevolent capitalism. To achieve this goal, all stakeholders including the government, community leaders/traditional rulers, youth leaders, political elites, women and entrepreneurs have mutually benefiting roles to play. Moreover, beneficiaries of the capitalist economic system whether at the individual level or at the national/corporate level must imbibe the spirit of altruism so they can give back to the poor people and nations that have, knowingly or naively, become the victims of the system.

\section{References}

[1]. Butterfoss F.D., and Kegler M.C. (2002) Toward a comprehensive understanding of community coalitions In: DiClemente RJ, Crosby RA, Kegler MC (editors) Emerging theories in health promotion practice and research: strategies for improving public health (1st ed., pp157-193)San Francisco: Jossey-Bass.

[2]. Cohen, S. and Zysman, J. (1987). Manufacturing Matters: The Myth of the Post-Industrial Economy. New York: Basic Books.

[3]. Eisinger, P.K. (1988) The Rise of the Entrepreneurial State: State and Local Economic Development Policy in the United States. Madison: University of Wisconsin Press.

[4]. Giddens, A. (2009) Sociology; Cambridge: Polity Press

[5]. Porter, M.E. (1995). "The Competitive Advantage of the Inner City," Harvard Business Review (May/June):55-71.

[6]. Reisman, G. (2002) Some Fundamental Insights Into the Benevolent Nature of Capitalism, available from http://www.capitalism.net/articles/Some $\% 20$ Fundamental $\% 20$ Insights $\% 20$ Into $\% 20$ the $\% 20$ Benevolent $\% 20$ Nature $\% 20$ of $\% 20$ Capital ism.html (accessed on 4/10/13) 